\title{
OS ACIDENTES E MORTES NO TRÂNSITO CAUSADOS PELO CONSUMO DE ÁLCOOL: UM PROBLEMA DE SAÚDE PÚBLICA
}

Traffic accidents and deaths due to alcohol consumption: a public health problem

${ }^{1}$ Universidade Federal de Pernambuco. Recife/PE, Brasil.

Correspondência: Nemésio Dario Almeida. E-mail: nemesiodario@hotmail.com.

Recebido em: 21/03/2014. Aprovado em: 08/05/2014. 


\section{RESUMO}

O presente estudo tem como objetivo revisar o problema do álcool e da direção e sua respectiva incorporação à agenda política brasileira, por meio de programas de prevenções, tratamentos e redução de danos. Durante as décadas de 1980 e 1990, as taxas dos acidentes de trânsito correspondiam a quase metade dos óbitos por causas externas, com tendências crescentes. Só nas últimas duas décadas do século XX que os acidentes de trânsito foram definidos como problemas de saúde pública e, dentro da discussão dos acidentes, violência e óbitos por causas externas, a combinação álcool e direção foi configurada como um problema que requer políticas públicas.

\section{Palavras-chave}

Álcool; Direção; Políticas Públicas; Redução de Danos.

\section{ABSTRACT}

This study aims to analyze drinking and driving issues and its corresponding incorporation in the Brazilian political agenda through prevention programs, treatment, and harm reduction. During the 1980s and 90s, traffic accident rates accounted for almost half of deaths by external causes, with a rising trend. Only in the last two decades of the twentieth century, traffic accidents were defined as public health problem. Within the discussion of accidents, violence, and deaths by external causes, the drinking and driving combination was configured as a problem that requires public policies.

\section{Keywords}

Alcohol; Driving; Harm Reduction; Public Polices. 


\section{Introdução}

Excelentes vias e carros tecnicamente perfeitos não vão fazer decrescer o lamentável número de acidentes fatais, se não se investir pesadamente na educação do homem para o trânsito ${ }^{1}$.

Com essa reflexão de Rozestraten, que discute a importância da educação do homem para o trânsito, introduzo este estudo, abordando inicialmente uma forma de transporte muito utilizada hoje, o carro, que também passou a ser considerado - por que não? - um prolongamento da personalidade e do corpo do motorista. Tem-se, então, que a cultura do automóvel tornou-se um fascínio para as pessoas, que também dá aos condutores uma posição distinta em relação aos outros atores do trânsito - pedestres, passageiros, ciclistas e motociclistas - principalmente na disputa e na concorrência pelo tempo e pelo espaço nas grandes cidades ${ }^{2,3,4,5,6}$.

É importante destacar que existe uma parcela numerosa da população sem posses, sem carro e sem condições seguras para andar pelas cidades (poucos equipamentos de segurança como ilhas de proteção, passarelas, faixas de retenção). Essas pessoas são vistas como um estorvo e, ao mesmo tempo, seus direitos são suprimidos enquanto cidadãos.

Essa situação provoca e reforça as condutas de transgressão e de risco no trânsito. Temos, então, que o consumo de álcool revela-se como uma principal causa dos acidentes de trânsito e, assim, os acidentes acontecem e as vítimas passam a fazer parte de estatísticas previsíveis e crescentes em vários países.

Na sociedade atual, o álcool e mesmo outras drogas continuam sendo usados pela maioria das pessoas de uma forma recreativa e, por alguns grupos, de maneira ritualística. Os usos recreativo e ritualístico não provocam qualquer dano ao indivíduo ou à sociedade. $\mathrm{O}$ álcool é uma substância psicoativa que pode, dependendo da dose, frequência e circunstância, ser ingerida sem problemas.

Entretanto, estudos recentes indicam que uma porcentagem importante da população adulta substitui os usos recreativo e ritualístico por outros, chamados de

${ }^{1}$ ROZESTRATEN, Reinier Johannes Antonius. Psicologia do trânsito: conceitos e processos básicos. São Paulo: EPU, 1988. p. 8.

${ }^{2}$ CONSELHO FEDERAL DE PSICOLOGIA. Referências técnicas para a prática de psicólogas(os) em Políticas de Mobilidade Urbana, Transporte e Trânsito. Versão preliminar para consulta pública - novembro de 2013. Disponível em: <http://crpsp.org.br/crepop/pdfs/politicas-publicas-de-mobilidade-urbana-transporte-e-transito.pdf>. Acesso em: 10 jan. 2014.

${ }^{3}$ LUDD, Ned (Org.). Apocalipse motorizado: a tirania do automóvel em um planeta poluído. São Paulo: Conrad Ed. do Brasil, 2005.

${ }^{4}$ NORONHA, Ana Paula; LOPES, Rebecca; AMBIEL, Rodolfo Augusto; SIQUEIRA, Gabriel Di Pierro. Consulta Pública do Documento de Referências Técnicas para Atuação de Psicólogas(os) nas Políticas Públicas de Mobilidade Urbana, Transporte e Trânsito, dezembro de 2013. Disponível em: <http://www.crpsp.org.br/ portal/comunicacao/2013_12_19_CREPOP/2013_12_19_CREPOP.html>. Acesso em: 10 jan. 2014.

5TAWIL, Marc. Trânsito assassino: as mortes aumentam, ninguém liga. São Paulo: Albatroz, 2007.

${ }^{6}$ MATTA, Roberto. Fé em Deus e pé na tábua. Ou como e por que o trânsito enlouquece no Brasil. Rio de Janeiro: Rocco, 2010. 
riscos e prejudiciais, que podem trazer graves consequências orgânicas, psicológicas e sociais ${ }^{7,8,9}$ como, por exemplo, determinados indivíduos que, em situação de lazer ou trafegando pela cidade, se expõem, assim como a terceiros, a situações de riscos, como indicam estudos nacionais ${ }^{10,11,12}$.

Infelizmente, o Brasil encontra-se ainda em estágio inicial de reconhecer o comportamento de dirigir alcoolizado como um grave problema de saúde pública ${ }^{13,14}$. As poucas estatísticas existentes apontam um quadro preocupante. Em um levantamento que objetivava conhecer a incidência do uso de álcool e anfetaminas entre caminhoneiros de estrada, feito com 91 motoristas abordados em um posto de combustíveis na cidade de Passos, no Estado de Minas Gerais, em novembro de 2005, cujos dados foram obtidos por meio de um questionário contendo 19 questões de múltipla escolha, os resultados indicaram que 66\% desses profissionais usavam anfetaminas durante os percursos de viagens, principalmente em postos de combustíveis (54\%) à beira das rodovias. O álcool era utilizado por $91 \%$ deles, dos quais $43 \%$ consumiam a bebida nos postos de combustíveis ${ }^{15}$. O estudo concluiu que há a necessidade de campanhas preventivas e informativas voltadas para esta categoria profissional nos postos de combustíveis e empresas de transportes, alertando sobre os riscos de ingestão dessas substâncias no período de trabalho.

Em outro estudo, foi efetuado um levantamento com a finalidade de estimar a prevalência do uso de álcool por motoristas conduzindo veículos e de testar a aceitabilidade dos bafômetros ativos e passivos. Foram avaliados 908 motoristas nas principais vias de trânsito na cidade de Diadema, Estado de São Paulo, de fevereiro

${ }^{7}$ GRANVILLE-GARCIA, Ana Flavia; CLEMENTINO, Marayza Alves; GOMES, Monalisa da Nobrega Cesarino; FIRMINO, Ramon Targino; RIBEIRO, Gabriella Lima Arrais; SIQUEIRA, Maria Betania Lins Dantas. Consumo de bebida alcoólica entre adolescentes: atitudes, comportamentos e fatores associados. Revista Ciência \& Saúde Coletiva, Rio de Janeiro, v. 19, n. 1, p. 7-16, 2014.

8JOMAR, Rafael Tavares; ABREU, Angela Maria Mendes; GRIEP, Rosane Harter. Padrões de consumo de álcool e fatores associados entre adultos usuários de serviço de atenção básica do Rio de Janeiro, RJ, Brasil. Revista Ciência \& Saúde Coletiva, Rio de Janeiro, v. 19, n. 1, p. 27-38, 2014.

${ }^{V}$ ARGAS, Divane de; BITTENCOURT, Marina Nolli; BARROSO, Lucia Pereira. Padrões de consumo de álcool de usuários de serviços de atenção primária à saúde de um município brasileiro. Revista Ciência \& Saúde Coletiva, Rio de Janeiro, v. 19, n. 1, p. 17-25, 2014.

${ }^{10}$ ALMEIDA, Nemésio Dario. A ingestão de álcool e direção no contexto universitário, comunicação persuasiva e prevenção: uma aplicação da Teoria da Ação Racional. 2010. 345f. Tese (Doutorado) - Programa de Pós-Graduação em Psicologia Cognitiva, Universidade Federal de Pernambuco. Recife, 2010.

${ }^{11}$ MINISTÉRIO DAS CIDADES. Brasil: um acidente a cada 30 segundos; duas indenizações a cada minuto - 2012. Brasília. Disponível em: <http://www.dpvatsegurodotransito.com.br/noticia2.aspx>. Acesso em: 10 jan. 2014.

${ }^{12}$ SILVA, Paul Hindenburg Nobre de Vasconcelos. Epidemiologia dos acidentes de trânsito com foco na mortalidade de motociclistas no Estado de Pernambuco: uma exacerbação da violência social. 2012. 140f. Tese (Doutorado) - Centro de Pesquisas Aggeu Magalhães, Fundação Oswaldo Cruz. Recife, 2012.

${ }^{13}$ ALMEIDA, Nemésio Dario. A saúde no Brasil, impasses e desafios enfrentados pelo Sistema Único de Saúde - SUS. Revista Psicologia e Saúde, Campo Grande, v. 5, n. 1, p. 1-9, 2013.

${ }^{14}$ ALVES, Vânia Sampaio; LIMA, Isabel Maria Sampaio Oliveira. Atenção à saúde de usuários de álcool e outras drogas no Brasil: convergência entre a saúde pública e os direitos humanos. Revista de Direito Sanitário, São Paulo, v. 13, n. 3, p. 9-32, 2013.

${ }^{15}$ NASCIMENTO, Eurípedes Costa do; NASCIMENTO, Evania; SILVA, José de Paula. Uso de álcool e anfetaminas entre caminhoneiros de estrada. Revista de Saúde Pública, São Paulo, v. 41, n. 2, p. 290-293, 2007. 
de 2005 a março de 2006. A metodologia adotada foi do tipo pontos de fiscalização de sobriedade, utilizada internacionalmente. Em 23,7\% dos motoristas foi encontrado algum traço de álcool no ar expirado e 19,4\% deles estavam com níveis de álcool iguais ou acima dos limites permitidos pela legislação.

O bafômetro passivo mostrou-se confiável e com resultados comparáveis aos do ativo. Esses achados foram seis vezes superiores aos encontrados internacionalmente, sugerindo a relevância desse problema ${ }^{16}$. São necessárias políticas específicas para combater esse problema, além de outras pesquisas em âmbito nacional.

De forma complementar, também foi conduzido um trabalho com o objetivo de estimar o consumo etílico em condutores de veículos que foram parados, em vias públicas de tráfego com maiores concentrações de bares, restaurantes e casas noturnas, em Belo Horizonte, Minas Gerais. Solicitou-se aos motoristas que respondessem a um questionário e fizessem o teste do bafômetro ativo. Essa pesquisa foi realizada nos meses de dezembro de 2005 e de dezembro de 2006, com 913 condutores. Para tanto, adotaram também a metodologia do tipo pontos de fiscalização de sobriedade.

A amostra revelou que $38 \%$ dos motoristas apresentavam algum traço de álcool no ar expirado e 19,6\% estavam com níveis de álcool acima dos limites legais. Esses dados foram cinco vezes maiores do que aqueles encontrados em pesquisas semelhantes em outros países ${ }^{17}$. Os achados desse estudo sugerem a relevância do problema na cidade de Belo Horizonte (e provavelmente no Brasil); a necessidade de pesquisas permanentes, o desenvolvimento de políticas públicas específicas para o assunto; e o eficaz cumprimento da lei existente.

Enquanto a legislação, a sociedade e a justiça brasileiras são excessivamente tolerantes com motoristas alcoolizados, a Europa e os Estados Unidos não fazem uma grande diferenciação entre um motorista alcoolizado que mata uma pessoa e o autor de um crime premeditado. Comparado com países mais adiantados na prevenção dos acidentes de trânsito, nossas leis, muitas vezes, são permissivas e sua aplicação, morosa.

De acordo com levantamento que procurou analisar a alcoolemia e os comportamentos de risco para acidentes de trânsito em jovens, antes e depois da implementação da lei que proibia o consumo de bebidas em postos de gasolina em Porto Alegre (RS), observou-se que os jovens tinham o hábito de comprar bebidas alcoólicas nas lojas de conveniência de postos de gasolina e consumi-las

\footnotetext{
${ }^{16}$ DUAILIBI, Sérgio; PINSKY, Ilana; LARANJEIRA, Ronaldo. Prevalência do beber e dirigir em Diadema, Estado de São Paulo. Revista de Saúde Pública, São Paulo, v. 41, n. 6, p. 1058-1061, 2007.

${ }^{17}$ CAMPOS, Valdir Ribeiro; SALGADO, Rogério; ROCHA, Mariela Campos; DUAILIBI, Sérgio; LARANJEIRA, Ronaldo. Prevalência do beber e dirigir em Belo Horizonte, Minas Gerais, Brasil. Cadernos de Saúde Pública, Rio de Janeiro, v. 24, n. 4, p. 829-834, 2008.
} 
nos estacionamentos dentro destes postos ${ }^{18}$. Os dados foram obtidos por meio de questionários autoaplicáveis e por testes de bafômetro em duas coletas transversais realizadas com jovens abordados em maio e julho de 2006, com amostragem intencional ( $n=62$ e $n=50$, respectivamente).

Não houve diferença significativa entre os grupos entrevistados. Alcoolemia menor que $0,6 \mathrm{~g} / \mathrm{l}$ foi encontrada em $35,5 \%$ e $40 \%$ dos jovens antes e depois da lei, respectivamente $(\mathrm{p}=0,62)$. Os resultados apontam o uso pesado de álcool em ambos os grupos, situação inalterada com a implementação da lei.

Em outro estudo, avaliou-se a presença de alcoolemia em vítimas fatais de acidentes de trânsito, no Distrito Federal, em 2005. De 442 óbitos, 163 foram resultantes de atropelamentos, 84 de capotagem e 195 de colisão. A alcoolemia foi dosada em 238 casos (53,7\%). A maioria das vítimas era jovem, entre 18 e 35 anos e do sexo masculino. Entre as vítimas de colisão, 44,2\% tinham níveis de alcoolemia acima de 0,6 g/l; nas vítimas de capotagens, esse percentual foi de 57,7\%; e, entre os pedestres, 32,5\%. A diferença entre as proporções de vítimas com alcoolemia positiva foi estatisticamente significativa para os que sofreram acidentes de capotagem em relação aos demais ${ }^{19}$.

Um estudo realizado durante o ano de 2012, pelo Observatório Nacional de Segurança Viária (ONSV) - com base nas solicitações de indenizações ao seguro obrigatório de veículos, Danos Pessoais Causados por Veículos Automotores de Via Terrestre (DPVAT) - mostrou que o número de vítimas de acidentes de trânsito é muito superior aos apresentados pelas estatísticas oficiais baseadas no Banco de Dados do Sistema Único de Saúde (Datasus) ${ }^{20}$. Mais de 60 mil mortos foram contabilizados em 2012, um acréscimo de 4\% em relação ao ano de 2011, e 352 mil ocorrências de invalidez permanente. Morre-se mais em acidentes de trânsito do que por homicídio ou câncer. Nós, brasileiros, temos mais motivos para temer um cidadão na direção ou sobre uma moto do que temermos a possibilidade de nos depararmos com um assaltante ou de enfrentarmos uma enfermidade.

Costuma-se apontar a precariedade das estradas, a infraestrutura deficiente, a falta de ciclovias e as falhas na sinalização como as causas para as tragédias no asfalto. Também se afirma que os carros vendidos aqui, que não passam nos padrões de segurança europeus, são verdadeiras armadilhas letais sobre rodas. Todos esses fatores aumentam os riscos, mas a maior razão para o massacre no trânsito é que nós, brasileiros, dirigimos muito mal. Mais de $95 \%$ dos desastres viários no país é

\footnotetext{
${ }^{18}$ DE BONI, Raquel; LEUKEFELD, Carl; PECHANSKY, Flavio. Alcoolemia de jovens e lei contra o consumo de álcool. Revista de Saúde Pública, São Paulo, v. 42, n. 6, p. 1101-1104, 2008.

${ }^{19}$ MODELLO, Manoel Eugenio dos Santos; PRATESI, Riccardo; TAUIL, Pedro Luiz. Alcoolemia em vítimas fatais de acidentes de trânsito no Distrito Federal, Brasil. Revista de Saúde Pública, São Paulo, v. 42, n. 2, p. 350-352, 2008.

${ }^{20}$ OBSERVATÓRIO NACIONAL DE SEGURANÇA VIÁRIA. Relatório anual de acidentes de carros em 2012. Disponível em: <http://www.onsv.org.br/Content/Upload/Downloads/Relatorio_Anual_2012.pdf>. Acesso em: 10 jan. 2014.
} 
resultado de uma combinação de irresponsabilidade e imperícia. O primeiro problema está relacionado à ineficácia do poder público na aplicação das leis e a nossa inclinação cultural para burlar regras. $\mathrm{O}$ segundo tem sua origem no foco excessivo em soluções arrecadatórias para o trânsito - multas, essencialmente - e quase nenhuma atenção à formação de motoristas e pedestres.

Outro estudo realizado pelo Centro de Pesquisas Jurídicas Aplicadas de Direito da Fundação Getúlio Vargas, em 2011, sobre o Índice de Percepção do Cumprimento da Lei (IPCL), revelou que $82 \%$ dos brasileiros acham fácil desobedecer às leis no país ${ }^{21}$.

Uma fiscalização eficiente e constante teria o poder de fazer os cidadãos abandonarem as condutas de risco até que a postura responsável se tornasse automática. Foi o que ocorreu, em certa medida, com o cinto de segurança. E é o que se tem tentado, até agora com pouco sucesso, com a embriaguez ao volante.

Em 2008, quando entrou em vigor a Lei Seca ${ }^{22}$, o impacto positivo foi imediato. Com medo de serem "pegos no bafômetro", muitos motoristas deixaram de conduzir depois de beber. Como consequência, no ano seguinte, houve uma redução de quase quatro mil pedidos de indenização por morte ao DPVAT. Bastou os motoristas descobrirem que não eram obrigados a soprar no bafômetro e que as blitz eram previsíveis, para que a curva de mortes retornasse à trajetória ascendente.

A nova versão da Lei Seca ${ }^{23}$, aprovada no fim do ano de 2012, permite a punição dos condutores embriagados mesmo sem o bafômetro. Em muitas capitais, porém, só são realizadas operações policiais durante a noite ou nos fins de semana. Em cidades pequenas, por sua vez, as autoridades frequentemente fazem vista grossa para as infrações de trânsito porque puni-las é considerada uma medida impopular - apesar de benéfica para a população. Esse paradoxo explica o aumento do número de vítimas envolvendo motocicletas. A situação é mais grave no Nordeste de onde, em 2012, vieram 27\% dos pedidos de indenização por morte no trânsito, muitos dos quais envolvendo motos.

Uma pesquisa feita pelo Departamento Estadual de Trânsito de São Paulo (Detran-SP), em julho de 2013, que ouviu 640 motoristas por meio de questionário online, revelou que um em cada quatro motoristas que saem à noite admite dirigir embriagado na capital. O levantamento também apontou a falta de percepção de

\footnotetext{
${ }^{21}$ FUNDAÇÃO GETÚLIO VARGAS. Centro de Pesquisas Jurídicas Aplicadas de Direito da Fundação Getúlio Vargas. 0 índice de percepção do cumprimento da lei - IPCL-Brasil-2012. Disponível em: <http://cpja.fgv.br/ sites/cpja.fgv.br/files/ipcl_relatorio_4tri2012_1tri2013_0.pdf>. Acesso em: 10 jan. 2014.

${ }^{22}$ BRASIL. Lei n. 11.705, de 19 de junho de 2008. Dispõe sobre a inibição do consumo de bebida alcoólica por condutor de veículos automotor e dá outras providências. Disponível em: <http://www.planalto.gov.br/ ccivil_03/_Ato2007-2010/2008/Lei/L11705.htm>. Acesso em: 10 jan. 2014.

${ }^{23}$ BRASIL. Lei n. 12.7760, de 20 de dezembro de 2012. Altera a Lei $n .9 .503$, de 23 de setembro de 1997, que institui o Código de Trânsito Brasileiro. Disponível em: <http://www.planalto.gov.br/ccivil_03/_Ato20112014/2012/Lei/L12760.htm>. Acesso em: 10 jan. 2014.
} 
risco em relação à bebida e direção: 47,7\% achavam que o álcool não os prejudica. Quase metade dos que confessaram dirigir embriagados $(47,7 \%)$ achavam que bebiam pouco e que isso não os prejudicava. Outros $22 \%$ disseram nunca ter se envolvido em acidentes e se julgavam bons motoristas.

Entre os argumentos para justificar esse comportamento, 69,7\% disseram que faziam isso por não terem opção e $34,1 \%$, por morarem perto do local. Essa falta de percepção de risco pessoal é preocupante, pois existe uma clara associação entre o álcool e o número de acidentes e mortes no trânsito. Entre os entrevistados, $35,7 \%$ frequentavam bares e restaurantes de três a cinco vezes por mês, na maioria das vezes às sextas-feiras $(85,2 \%)$ e aos sábados $(95,7 \%)^{24}$.

De acordo com o Relatório Global de Segurança no Trânsito 2013, publicado pela Organização Mundial da Saúde (OMS), 88 países-membros conseguiram reduzir o número de vítimas fatais; por outro lado, esse número cresceu em 87 países $^{25}$. A chave para a redução da mortalidade, segundo o relatório, é garantir que os Estados-Membros adotem leis que cubram os cinco principais fatores de risco: dirigir sob o efeito de álcool, excesso de velocidade, não uso do capacete, do cinto de segurança e das cadeiras para crianças. Apenas 28 países, que abrigam $7 \%$ da população mundial, possuem leis abrangentes nesses cinco fatores. O relatório ainda destaca que:

- 89 países, cobrindo $66 \%$ da população mundial, têm legislação sobre a ingestão de bebida alcoólica e a direção, com limite de álcool no sangue de $0,05 \mathrm{~g} / \mathrm{dl}$ ou menor, conforme recomendado pela OMS;

- 90 países, cobrindo $77 \%$ da população mundial, têm leis que obrigam o uso de capacete;

- 111 países, cobrindo $69 \%$ da população mundial, têm leis que obrigam o uso do cinto de segurança para todos os ocupantes;

- 96 países, cobrindo 32\% da população mundial, têm uma legislação que exige o uso de cadeiras para crianças.

O documento também aponta que, na maioria dos países, - mesmo entre aqueles com melhores resultados - a aplicação das leis é inadequada.

O relatório identifica ainda os grupos com maior risco de morrer em acidentes de trânsito:

- 59\% das vítimas fatais estão na faixa etária dos 15 aos 44 anos e 77\% são homens;

\footnotetext{
${ }^{24}$ DEPARTAMENTO ESTADUAL DE TRÂNSITO DE SÃO PAULO. Uma em cada quatro pessoas que saem à noite admite dirigir embriagada na Capital paulista, em julho de 2013. Disponível em: <http://www.detran. sp.gov.br>. Acesso em: 10 jan. 2014.

${ }^{25}$ ORGANIZAÇÃO MUNDIAL DA SAÚDE. Relatório Global de Segurança no Trânsito 2013. Disponível em: <http:// www.who.int/violence_injury_prevention/road_safety_status/2013/en/>. Acesso em 10 jan. 2014.
} 
- pedestres e ciclistas representam $27 \%$ de todas as mortes no trânsito. Em alguns países, esse percentual é superior a 75\%, resultado de décadas de negligência com a segurança desses usuários nas políticas públicas, em favor do transporte motorizado;

- o risco de morrer em um acidente de trânsito é maior na África (24,1 a cada 100 mil pessoas) e menor da Europa (10,3 a cada $100 \mathrm{mil})$.

Ainda conforme o relatório, o Brasil, embora com aplicação deficiente, possui legislação específica para todos os cinco fatores de risco. Mesmo assim, o país não conseguiu reduzir os índices da acidentalidade.

Todos os estudos acima indicam que grande parte dos acidentes de trânsito não é casual, sendo passível de prevenção. Os acidentes de trânsito são decorrentes de um conjunto de circunstâncias e fatores ligados ao indivíduo, ao veículo e à via pública. Dentre os fatores ligados ao indivíduo, destacamos o consumo prejudicial do álcool. A grande incidência dos acidentes motivados, direta ou indiretamente, pelo uso de bebidas alcoólicas pode estar relacionada às mudanças de comportamento provocadas por esse uso - prepotência, liberação da censura, diminuição ou ausência da crítica, entre outros -, tanto nos condutores de veículos quanto nos pedestres.

Também há evidências de que as expectativas e crenças relacionadas aos efeitos do álcool são formadas em um período da vida anterior àquele onde se começa a consumir bebidas alcoólicas e são fortemente influenciadas pelos hábitos alcoólicos familiares, por atividades culturalmente estimulantes e pela mídia ${ }^{26}$.

\section{Os programas de prevenção e tratamento do uso de álcool}

São consideradas políticas do álcool aquelas que dizem respeito à relação entre álcool, segurança, saúde e bem-estar social. Definem-se políticas do álcool como sendo qualquer esforço ou decisão de autoridades governamentais ou de organizações não governamentais (ONGs), para minimizar ou prevenir problemas relacionados ao álcool. Quem faz a política do álcool? A resposta a esta pergunta difere entre países e entre níveis diferentes de governo de cada país. Leis federais e nacionais frequentemente estabelecem as bases legais para a prevenção e as políticas de tratamento. Em muitas nações, como o Brasil, há um vazio em advocacia pública, propiciando que ONGs sejam prováveis candidatas para representarem o público nos assuntos relacionados ao consumo de álcool ${ }^{27}$.

${ }^{26}$ ALMEIDA, Nemésio Dario. Promoção e divulgação de medidas educativas em circulação humana: em questão o fenômeno trânsito brasileiro. Revista Psicologia Argumento, Curitiba, v. 24, n. 46, p. 45-53, 2006.

${ }^{27}$ BABOR, Thomas; CAETANO, Raul; CASSWELL, Sally; EDWARDS, Griffith; GIESBRECHT, Norman; GRAHAM, Kathtyn; GRUBE, Joel; GRUENEWALD, P; HILL, Linda; HOLDER, Harold; HOMEL, Ross; ÖSTERBERG, Esa; REHM, Jürgen; ROOM, Robin; ROSSOW, Ingeborg. Alcohol: no ordinary commodity - research and public policy. Oxford and London: Oxford University Press, 2003 
Existente em quase todos os países, os Alcoólicos Anônimos (AAs), grupo de apoio aos dependentes de álcool fundado em 1935 (Akron, Ohio, Estados Unidos), expandiu sua forma de atuação em todo o mundo. Atualmente, o AA está presente em mais de 140 países, com cerca de 50 mil grupos. Estima-se que, desde a sua criação, mais de dois milhões de dependentes do álcool já se recuperaram por meio dos AAs. No Brasil, a associação teve seu início na cidade do Rio de Janeiro em 1948; avalia-se que existam mais de três mil grupos do AA no país ${ }^{28}$.

De certa forma, os AAs constituem-se como uma instituição de tratamento bem sucedida e que faz uso de métodos simples, em um tempo em que as técnicas estão cada vez mais elaboradas. A sua perspectiva principal baseia-se no conceito de alcoolismo como doença, em não deixar passar despercebido o trabalho em relação aos outros aspectos da vida do dependente do álcool e, o mais importante, em não se restringir apenas ao ato do consumo abusivo do álcool. Por meio de testemunhos de vida, o predomínio é o confronto usado com bastante propriedade para chamar a atenção do alcoolista sobre seus mecanismos de defesa e facilitar uma forma de autoavaliação. Ao mesmo tempo, só o fato de ser recepcionado como um ser humano, sendo compreendido e respeitado em suas limitações, permite uma melhora da autoestima muitas vezes comprometida, por conta do abuso do álcool ${ }^{29}$.

Tem-se também os grupos familiares como o AL-ANON, uma extensão do AAs, que trabalha para apoiar e ajudar os familiares do alcoolista e instruí-los sobre como conviver com o problema.

Do mesmo modo, temos o movimento conhecido como Amor Exigente (AE), outro programa com grupos de auto e mútua ajuda. O AE desenvolve preceitos para a organização da família, que são praticados por meio dos 12 Princípios Básicos e Éticos da Espiritualidade, e atua por meio de grupos de voluntários para sensibilizar as pessoas, levando-as a perceberem a necessidade de mudar o rumo de suas vidas e do mundo a partir de si mesmas.

Há mais de 30 anos, o AE atua como apoio e orientação aos familiares de dependentes químicos. O eficaz programa estendeu-se também ao trabalho de prevenção, passando a atuar como um movimento de proteção social, uma vez que o AE desestimula a experimentação, o uso ou o abuso de tabaco, do álcool e de outras drogas, assim como luta contra tudo o que torna os jovens vulneráveis, expostos à violência, ao crime, aos acidentes de trânsito e à corrupção em todas as suas formas. Atualmente, o movimento conta com mais de 11 mil voluntários, que realizam, aproximadamente, 100 mil atendimentos mensais por meio de reuniões, cursos e palestras. São mais de 700 grupos no Brasil, na Argentina e no Uruguai, além de 259 subgrupos frutos do AE.

\footnotetext{
${ }^{28}$ ALMEIDA, Nemésio Dario. A ingestão de álcool e direção no contexto universitário, comunicação persuasiva e prevenção: uma aplicação da Teoria da Ação Racional, cit.

${ }^{29}$ Id. Ibid.
} 
Outro programa atualmente importante dirigido aos usuários de álcool e de outras drogas são os Centros de Atenção Psicossocial - Álcool e Drogas (CAPS-AD), também chamados de serviços comunitários de saúde. Eles foram criados a partir de 1980, sob a égide da Reforma Psiquiátrica, e aspiram outra lógica, outra fundamentação teórica-técnica, uma nova ética que não mais se apoia no paradigma psiquiátrico baseado no modelo hospitalocêntrico, na qual o cuidar, o escutar atentamente chegam a designar uma parte fundamental do contorno que se pretende imprimir às ações de atenção psicossocial nas práticas de saúde no contexto brasileiro atual ${ }^{30}$.

Assim, esses centros de atenção seguem a lógica consagrada, no âmbito da saúde mental, da não internação, da integralidade e da organização em rede dos serviços de saúde. São espaços para a reabilitação, a integração e a inclusão social. Baseiam-se na lógica dos projetos de atenção individualizada, ou seja, são elaborados a partir de um plano multidisciplinar, de acordo com as necessidades detectadas no momento. Partindo desse princípio, os atendimentos grupais, a atenção à família, o resgate da cidadania, as oficinas, as práticas expressivas e outras intervenções terapêuticas poderão ser usadas com o objetivo da reabilitação.

De forma geral, o CAPS-AD é um serviço de saúde mental aberto, de caráter substitutivo à internação psiquiátrica, voltado para o atendimento de pessoas com dependências químicas, considerando não só a sintomatologia, mas os aspectos do convívio social. Tal serviço tem como missão possibilitar, de forma humanizada, a reinserção psicossocial do dependente químico na sociedade, por meio de intervenções realizadas por equipe interdisciplinar que visam a criar condições para desenvolver as potencialidades e as aptidões dos indivíduos. Assim sendo, sua proposta terapêutico-metodológica está respaldada nos princípios e diretrizes do Sistema Único de Saúde (SUS) ${ }^{31}$.

O projeto de recuperação sem a internação compulsória é o desafio das equipes dos CAPS-AD. Esse modelo terapêutico, já implementado em várias capitais brasileiras, está previsto nas portarias do Ministério da Saúde GM n. 336/2002 $2^{32}$ e GM n. 817/2002 ${ }^{33}$. É importante sinalizar a oportunidade dessa iniciativa do Ministério da Saúde, respaldada por recomendação da $3^{\text {a }}$ Conferência Nacional de Saúde Mental, sobretudo por se contrapor a uma histórica omissão das políticas públicas para essa questão.

\footnotetext{
${ }^{30}$ SARACENO, Benedetto. Reabilitação psicossocial: uma estratégia para a passagem do milênio. In: PITTA, Ana (Org.). Reabilitação psicossocial no Brasil. 2.ed. São Paulo: HUTEC, 2001. p. 13-18.

${ }^{31}$ Id. Ibid.

${ }^{32}$ MINISTÉRIO DA SAÚDE. Portaria n. 336/GM, de 19 fevereiro de 2002. Redefine e amplia a abrangência dos CAPS, estabelecendo portes diferenciados a partir de critérios populacionais, e direcionando novos serviços específicos para área de álcool e outras drogas. Disponível em: <http://dtr2001.saude.gov.br/ sas/PORTARIAS/Port2002/Gm/GM-336.htm>. Acesso em: 19 dez. 2013.

${ }^{33}$ MINISTÉRIO DA SAÚDE. Portaria n. 817/GM, de 30 de abril de 2002. Inclui na Tabela de Procedimentos SIH-SUS os procedimentos referentes à internação por uso prejudicial de álcool e drogas. Disponível em: <http:// dtr2001.saude.gov.br/sas/PORTARIAS/Port2002/Gm/GM-817.htm>. Acesso em: 7 dez. 2013.
} 
Na área da prevenção do alcoolismo, o que vale também para outras drogas, o Brasil dispõe, atualmente, de uma importante tecnologia: os programas que se apresentam têm em comum a dimensão de formação de agentes comunitários, valorizando a cultura popular, a renúncia das técnicas que provocavam medo, dando lugar a outras que procuram dar suporte às pessoas em suas singularidades por meio de uma inserção social criativa e produtiva ${ }^{34}$.

\section{0 custo efetividade das políticas públicas e os programas de redução de danos no trânsito}

Ao se reconhecer que o consumo de álcool e outras drogas não pode ser completamente abolido, podemos admitir procedimentos que visem a minimizar as suas consequências. Esses mecanismos são o que hoje se denominam de políticas de redução de danos.

Em sentido mais amplo, tem-se que as estratégias apresentadas para a efetividade das políticas públicas relacionadas ao controle do consumo de álcool são menos custosas em comparação aos gastos decorrentes dos problemas causados pela ingestão de bebidas alcoólicas. Exemplo disso é a instituição da idade mínima para a compra de bebidas, medida de custo insignificante e de grande impacto. O gasto com a implantação de tais medidas tende a se elevar quando se encontram resistências. Interesses comerciais podem dificultar a implantação de medidas de zoneamento ou de outras destinadas a regulamentar a distribuição geográfica dos pontos de venda. Inversamente, o custo diminui quanto maior o apoio popular às medidas implantadas ${ }^{35}$.

Levando-se em conta o valor das políticas públicas para o controle do consumo de álcool para saúde, segurança e economia internacional, a OMS ${ }^{36}$ realizou um levantamento com a participação de vários especialistas de nove países para avaliar diferentes políticas de consumo de bebidas alcoólicas. Foi criada uma lista com as "10 melhores práticas" com base nos seguintes critérios: evidência de efetividade, existência de suporte científico, possibilidade de transposição para diferentes culturas e custos de implementação e sustentação.

Cinco práticas são referentes a políticas de controle de álcool (regulatórias): (1) estabelecimento (e fiscalização) de idade mínima legal para compra de bebidas alcoólicas; (2) monopólio governamental das vendas de bebida no varejo; (3) restrição dos horários ou dos dias de venda; (4) restrições de densidade dos pontos de venda de álcool; e (5) criação de impostos para o álcool.

\footnotetext{
${ }^{34}$ CALDAS, Marco Túlio. Alcoolismo e prevenção: um estudo descritivo das idéias em prevenção do alcoolismo no Brasil. Revista Symposium, Recife, v. 9, n. 1, p. 56-61, 2005.

${ }^{35}$ DUAILIBI, Sérgio; LARANJEIRA, Ronaldo. Políticas públicas relacionadas às bebidas alcoólicas. Revista de Saúde Pública, São Paulo, v. 41, n. 5, p. 839-848, 2007.

${ }^{36}$ WORLD HEALTH ORGANIZATION. Fifty-Eighth World Health Assembly. A58/18. Provisional agenda item 13.14. 7 April 2005. Public health problems caused by harmful use of alcohol. Report by the Secretariat. Geneva. Disponivel em: <http://www.who.int/substance_abuse/publications/pdf>. Acesso em: 10 jan. 2014.
} 
Outras quatro práticas estão diretamente relacionadas com o controle do beber e dirigir: (1) redução do limite de concentração sanguínea do álcool permitida para dirigir; (2) suspensão administrativa da licença de motoristas que dirigem alcoolizados; (3) estabelecimento de postos de fiscalização de sobriedade; e (4) política de "tolerância zero" quanto ao dirigir alcoolizado, por vários anos, no licenciamento para motoristas novatos. A última prática é a instituição de processos terapêuticos do tipo intervenções breves para bebedores com uma dependência já instalada.

Algumas estratégias políticas são bastante populares, porém, sua eficácia é reduzida por apresentarem baixa efetividade e alto custo ${ }^{37,38}$ :

- promoção de atividades alternativas de lazer e diversão "livres de álcool" (como esportes) e abordagens efetivas direcionadas à clarificação de valores, autoestima e habilidades sociais;

- prevenção nas escolas: o objetivo dos programas escolares é modificar crenças, atitudes e comportamentos dos adolescentes em relação ao álcool. Embora aumentem o conhecimento, não modificam o consumo. Além disso, fornecer informações sobre os perigos de diferentes substâncias psicoativas pode despertar a curiosidade e estimular o consumo entre aqueles que buscam estímulos;

- mensagens publicitárias: embora possua apelo popular, a propaganda educativa nunca é tão bem produzida, nem possui os mesmos recursos e frequência nos meios de comunicação do que a propaganda da indústria do álcool. Apresenta alguma efetividade enquanto parte integrante de um programa mais amplo de políticas. Proibir a publicidade do álcool custa bem menos e é bem mais eficaz do que qualquer medida de contrapropaganda.

Dessa forma, tem-se que reduzir danos significa diminuir os agravos que podem advir do consumo de determinada substância psicotrópica como o álcool. Estes danos podem ser orgânicos, pois o uso do álcool pode afetar a saúde do usuário de várias maneiras, dependendo do seu organismo, da frequência do uso e da quantidade consumida. Porém, muitas consequências não são decorrentes diretamente do consumo etílico, mas sim de uma série de riscos aos quais o usuário pode expor-se sob efeito da bebida ${ }^{39}$.

\footnotetext{
${ }^{37}$ BABOR, Thomas; CAETANO, Raul; CASSWELL, Sally; EDWARDS, Griffith; GIESBRECHT, Norman; GRAHAM, Kathtyn; GRUBE, Joel; GRUENEWALD, P; HILL, Linda; HOLDER, Harold; HOMEL, Ross; ÖSTERBERG, Esa; REHM, Jürgen; ROOM, Robin; ROSSOW, Ingeborg. op. cit.

${ }^{38} \mathrm{CHISHOLM}$, Dan; REHM, Jürgen; VAN OMMEREN, Mark; MONTEIRO, Maristela. Reducing the global burden of hazardous alcohol use: a comparative cost-effectiveness analysis. Journal of Studies on Alcohol and Drugs, New Jersey, v. 65, n. 6, p. 782-793, 2004.

${ }^{39}$ MINISTÉRIO DA SAÚDE. Álcool e redução de danos: uma abordagem inovadora para países em transição. Brasília, 2004. Disponível em: <http://bvsms.saude.gov.br/bvs/publicacoes/alcool_reducao_danos2004. pdf>. Acesso em: 19 dez. 2013.
} 
Diariamente, as pessoas convivem com o trânsito caótico das grandes cidades brasileiras, dirigindo veículos ou transitando a pé sob o efeito etílico. Muitos danos não atingem somente quem consome álcool, mas também outras pessoas, numa reação em cadeia que mostra que drogas não são apenas uma questão de quem as usa. As estratégias de redução de danos tentam dar resposta a essa pluralidade de situações no âmbito das políticas públicas. As políticas de redução de danos buscam, principalmente, atenuar as consequências adversas do consumo de álcool, em vez de reduzir o consumo propriamente dito. Será que isso é possível no trânsito?

Reconhecendo que nenhuma política é efetiva, a menos que seja fiscalizada permanentemente, um estudo nacional mostrou que adolescentes de idade de 13 a 17 anos conseguiram facilmente comprar bebidas alcoólicas em diferentes tipos de estabelecimentos. Sem multa e fiscalização adequada, dificilmente poderia haver condições de promover uma melhora nessa situação. O que funciona realmente é a certeza de que uma determinada infração será punida ${ }^{40}$.

Constata-se então que as políticas e as leis são restritivas e direcionadas para o comportamento do condutor: inibindo a velocidade, o consumo etílico, além das penalidades aos infratores; quase nada se faz em termos de prevenção, educação e intervenção com a finalidade de aumentar a consciência e mudar a cultura e os valores sociais da população em relação ao trânsito e ao uso do álcool.

De forma complementar, algumas ingerências atuais do Ministério da Saúde $^{41}$, conforme indicações citadas anteriormente ${ }^{42,43}$, no que se refere às normas da redução de danos, têm tentado tornar mais seguros os veículos - carros, motocicletas, bicicletas - e as vias públicas, como também, buscado a execução de estratégias para evitar e/ou reduzir as situações de risco no trânsito para pedestres e motoristas. Entre elas, enfatizamos:

- programas que concedem transporte, gratuito ou não, para pessoas alcoolizadas, tornando mais segura sua chegada em casa;

- programas do tipo "amigo da vez" que incentivam um grupo de pessoas a escolher um membro para abster-se de beber naquela ocasião;

- blitz educativa. Policiais e educadores de trânsito, intervindo no fluxo de veículos e de pessoas, solicitando o uso de bafômetro para aferição da alcoolemia e repassando informações úteis sobre beber e transitar;

\footnotetext{
${ }^{40}$ ROMANO, Marcos; DUAILIBI, Sérgio; PINSKY, Ilana; LARANJEIRA, Ronaldo. Pesquisa de compra de bebidas alcoólicas por adolescentes em duas cidades do Estado de São Paulo. Revista de Saúde Pública, São Paulo, v. 41, n. 4, p. 495-501, 2007.

${ }^{41}$ MINISTÉRIO DA SAÚDE. Álcool e redução de danos: uma abordagem inovadora para países em transiçã, cit.

${ }^{42}$ BABOR, Thomas; CAETANO, Raul; CASSWELL, Sally; EDWARDS, Griffith; GIESBRECHT, Norman; GRAHAM, Kathtyn; GRUBE, Joel; GRUENEWALD, P; HILL, Linda; HOLDER, Harold; HOMEL, Ross; ÖSTERBERG, Esa; REHM, Jürgen; ROOM, Robin; ROSSOW, Ingeborg. op. cit.

${ }^{43}$ CHISHOLM, Dan; REHM, Jürgen; VAN OMMEREN, Mark; MONTEIRO, Maristela. op. cit., p. 782-793.
} 
- campanhas educativas frequentes sobre comportamentos seguros e éticos que estimulem a segurança, a cordialidade e a solidariedade no trânsito.

Diferentes estratégias de redução de danos devem ser pensadas e formuladas na tentativa de se aproximar de grupos que, por suas características, se tornam mais indefesos no trânsito, como pedestres, crianças, gestantes e idosos. Por fim, é importante salientar que a execução de programas de redução de danos constitui um caminho seguro para um decréscimo dos comportamentos de risco relacionados à ingestão de etílicos no trânsito.

\section{Considerações finais}

Constatamos que foi nas últimas duas décadas do século XX que os acidentes de trânsito passaram a ser definidos como problema de saúde pública, tendo em vista os altíssimos custos financeiros e sociais que deles decorrem e, no que diz respeito ao debate em relação a acidentes, violência e óbitos por causas externas, a mistura do consumo de álcool e direção automotiva foi formatada como um problema que requer políticas públicas. $\mathrm{O}$ aumento dos acidentes dá uma projeção indispensável para que essa questão seja propalada na mídia e alcance a opinião pública. A mídia é nutrida pelas pesquisas, dados estatísticos de órgãos de trânsitos, por estudiosos no assunto, campanhas sociais, bem como pelas ações de organizações como a OMS e ONGs que atuam com a problemática do álcool e dos acidentes de trânsito. Tais ações vêm ocasionar uma pressão lenta, mas firme, na agenda pública.

Infelizmente, constatamos uma tensão em alguns campos de atuação em que interesses colidentes estão presentes ao tema álcool e direção. De um lado, a questão de saúde pública, de outro, a defesa do mercado livre e autorregulado. E, no meio disso tudo, as políticas públicas brasileiras que se encontram em fase de implementação, intercedidas por diversas barreiras. Como num processo, as análises aqui apresentadas são atravessadas por uma política em fase de consolidação: há muito ainda que se tratar sobre ela. Tem-se ainda que discutir a função da mídia nesse processo, a deficitária regulação da propaganda do álcool e a mudança de atitude em relação ao uso e venda de bebidas alcoólicas como uma questão de livre mercado.

\section{Referências}

ALMEIDA, Nemésio Dario. A ingestão de álcool e direção no contexto universitário, comunicação persuasiva e prevenção: uma aplicação da Teoria da Ação Racional. 2010. 345f. Tese (Doutorado) - Programa de Pós-Graduação em Psicologia Cognitiva, Universidade Federal de Pernambuco. Recife, 2010.

Promoção e divulgação de medidas educativas em circulação humana: em questão o fenômeno trânsito brasileiro. Revista Psicologia Argumento, Curitiba v. 24, n. 46, p. 45-53, 2006. 
Acidentes no trânsito e consumo de álcool: um problema de saúde pública

ALMEIDA, Nemésio Dario. A saúde no Brasil, impasses e desafios enfrentados pelo Sistema Único de Saúde-SUS. Revista Psicologia e Saúde, Campo Grande, v. 5, n. 1, p. 1-9, 2013.

ALVES, Vânia Sampaio; LIMA, Isabel Maria Sampaio Oliveira. Atenção à saúde de usuários de álcool e outras drogas no Brasil: convergência entre a saúde pública e os direitos humanos. Revista de Direito Sanitário, São Paulo, v. 13, n. 3, p. 9-32, 2013.

BABOR, Thomas; CAETANO, Raul; CASSWELL, Sally; EDWARDS, Griffith; GIESBRECHT, Norman; GRAHAM, Kathtyn; GRUBE, Joel; GRUENEWALD, P; HILL, Linda; HOLDER, Harold; HOMEL, Ross; ÖSTERBERG, Esa; REHM, Jürgen; ROOM, Robin; ROSSOW, Ingeborg. Alcohol: no ordinary commodity - research and public policy. Oxford and London: Oxford University Press, 2003.

CALDAS, Marco Túlio. Alcoolismo e prevenção: um estudo descritivo das idéias em prevenção do alcoolismo no Brasil. Revista Symposium, Recife, v. 9, n. 1, p. 56-61, 2005.

CAMPOS, Valdir Ribeiro; SALGADO, Rogério; ROCHA, Mariela Campos; DUAILIBI, Sérgio; LARANJEIRA, Ronaldo. Prevalência do beber e dirigir em Belo Horizonte, Minas Gerais, Brasil. Cadernos de Saúde Pública, Rio de Janeiro v. 24, n. 4, p. 829-834, 2008.

CHISHOLM, Dan; REHM, Jürgen; VAN OMMEREN, Mark; MONTEIRO, Maristela. Reducing the global burden of hazardous alcohol use: a comparative cost-effectiveness analysis. Journal of Studies on Alcohol and Drugs, New Jersey, v. 65, n. 6, p. 782-793, 2004.

CONSELHO FEDERAL DE PSICOLOGIA. Referências técnicas para a prática de psicólogas(os) em Políticas de Mobilidade Urbana, Transporte e Trânsito. Versão preliminar para consulta pública - novembro de 2013. Disponível em: <http://crpsp.org.br/crepop/pdfs/politicaspublicas-de-mobilidade-urbana--transporte-e-transito.pdf>. Acesso em: 10 jan. 2014.

DE BONI, Raquel; LEUKEFELD, Carl; PECHANSKY, Flavio. Alcoolemia de jovens e lei contra o consumo de álcool. Revista de Saúde Pública, São Paulo, v. 42, n. 6, p. 1101-1104, 2008.

DEPARTAMENTO ESTADUAL DE TRÂNSITO DE SÃO PAULO. Uma em cada quatro pessoas que saem à noite admite dirigir embriagada na Capital paulista, em julho de 2013. Disponível em: <http://www.detran.sp.gov.br>. Acesso em: 10 jan. 2014.

DUAILIBI, Sérgio; LARANJEIRA, Ronaldo. Políticas públicas relacionadas às bebidas alcoólicas. Revista de Saúde Pública, São Paulo, v. 41, n. 5, p. 839-848, 2007.

; PINSKY, Ilana; LARANJEIRA, Ronaldo. Prevalência do beber e dirigir em Diadema, Estado de São Paulo. Revista de Saúde Pública, São Paulo, v. 41, n. 6, p. 1058-1061, 2007.

FUNDAÇÃO GETÚlIO VARGAS. Centro de Pesquisas Jurídicas Aplicadas de Direito da Fundação Getúlio Vargas. O índice de percepção do cumprimento da lei - IPCL-Brasil-2012. Disponível em: <http://cpja.fgv.br/sites/cpja.fgv.br/files/ipcl_relatorio_4tri2012_1tri2013_0. pdf $>$. Acesso em: 10 jan. 2014. 
GRANVILLE-GARCIA, Ana Flavia; CLEMENTINO, Marayza Alves; GOMES, Monalisa da Nobrega Cesarino; FIRMINO, Ramon Targino; RIBEIRO, Gabriella Lima Arrais; SIQUEIRA, Maria Betania Lins Dantas. Consumo de bebida alcoólica entre adolescentes: atitudes, comportamentos e fatores associados. Revista Ciência \& Saúde Coletiva, Rio de Janeiro, v. 19, n. 1, p. 7-16, 2014.

JOMAR, Rafael Tavares; ABREU, Angela Maria Mendes; GRIEP, Rosane Harter. Padrões de consumo de álcool e fatores associados entre adultos usuários de serviço de atenção básica do Rio de Janeiro, RJ, Brasil. Revista Ciência \& Saúde Coletiva, Rio de Janeiro v. 19, n. 1, p. 27-38, 2014.

LUDD, Ned (Org.). Apocalipse motorizado: a tirania do automóvel em um planeta poluído. São Paulo: Conrad Ed. do Brasil, 2005.

MATTA, Roberto. Fé em Deus e pé na tábua. Ou como e por que o trânsito enlouquece no Brasil. Rio de Janeiro: Rocco, 2010.

MINISTÉRIO DAS CIDADES. Brasil: um acidente a cada 30 segundos; duas indenizações a cada minuto - 2012. Brasília. Disponível em: <http://www.dpvatsegurodotransito.com.br/ noticia2.aspx>. Acesso em: 10 jan. 2014.

MINISTÉRIO DA SAÚDE. Álcool e redução de danos: uma abordagem inovadora para países em transição. Brasília, 2004. Disponível em: <http://bvsms.saude.gov.br/bvs/publicacoes/ alcool_reducao_danos2004.pdf>. Acesso em: 19 dez. 2013.

MODELLO, Manoel Eugenio dos Santos; PRATESI, Riccardo; TAUIL, Pedro Luiz. Alcoolemia em vítimas fatais de acidentes de trânsito no Distrito Federal, Brasil. Revista de Saúde Pública, São Paulo, v. 42, n. 2, p. 350-352, 2008.

NASCIMENTO, Eurípedes Costa do; NASCIMENTO, Evania; SILVA, José de Paula. Uso de álcool e anfetaminas entre caminhoneiros de estrada. Revista de Saúde Pública, São Paulo, v. 41, n. 2, p. 290-293, 2007.

NORONHA, Ana Paula; LOPES, Rebecca; AMBIEL, Rodolfo Augusto; SIQUEIRA, Gabriel Di Pierro. Consulta Pública do Documento de Referências Técnicas para Atuação de Psicólogas(os) nas Políticas Públicas de Mobilidade Urbana, Transporte e Trânsito, dezembro de 2013. Disponível em: <http://www.crpsp.org.br/portal/comunicacao/2013_12_19_ CREPOP/2013_12_19_CREPOP.html>. Acesso em: 10 jan. 2014.

OBSERVATÓRIO NACIONAL DE SEGURANÇA VIÁRIA. Relatório anual de acidentes de carros em 2012. Disponível em: <http://www.onsv.org.br/Content/Upload/Downloads/ Relatorio_Anual_2012.pdf>. Acesso em: 10 jan. 2014.

ORGANIZAÇÃO MUNDIAL DA SAÚDE. Relatório Global de Segurança no Trânsito 2013. Disponível em: $<$ http://www.who.int/violence_injury_prevention/road_safety_status/2013/ en/>. Acesso em 10 jan. 2014.

ROMANO, Marcos; DUAILIBI, Sérgio; PINSKY, Ilana; LARANJEIRA, Ronaldo. Pesquisa de compra de bebidas alcoólicas por adolescentes em duas cidades do Estado de São Paulo. Revista de Saúde Pública, de São Paulo, v. 41, n. 4, p. 495-501, 2007. 
Acidentes no trânsito e consumo de álcool: um problema de saúde pública

ROZESTRATEN, Reinier Johannes Antonius. Psicologia do trânsito: conceitos e processos básicos. São Paulo: EPU, 1988.

SARACENO, Benedetto. Reabilitação psicossocial: uma estratégia para a passagem do milênio. In: PITTA, Ana (Org.). Reabilitação psicossocial no Brasil. 2.ed. São Paulo: HUTEC, 2001.

SILVA, Paul Hindenburg Nobre de Vasconcelos. Epidemiologia dos acidentes de trânsito com foco na mortalidade de motociclistas no Estado de Pernambuco: uma exacerbação da violência social. 2012. 140f. Tese (Doutorado) - Centro de Pesquisas Aggeu Magalhães, Fundação Oswaldo Cruz. Recife, 2012.

TAWIL, Marc. Trânsito assassino: as mortes aumentam, ninguém liga. São Paulo: Albatroz, 2007.

VARGAS, Divane de; BITTENCOURT, Marina Nolli; BARROSO, Lucia Pereira. Padrões de consumo de álcool de usuários de serviços de atenção primária à saúde de um município brasileiro. Revista Ciência \& Saúde Coletiva, Rio de Janeiro v. 19, n. 1, p. 17-25, 2014.

WORLD HEALTH ORGANIZATION. Fifty-Eighth World Health Assembly. A58/18. Provisional agenda item 13.14. 7 April 2005. Public health problems caused by harmful use of alcohol. Report by the Secretariat. Geneva. Disponível em: <http://www.who.int/ substance_abuse/publications/pdf $>$. Acesso em: 10 jan. 2014.

Nemésio Dario Almeida - Doutor em Psicologia pela Universidade Federal de Pernambuco; Pesquisador do Núcleo de Pesquisa em Epistemologia Experimental e Cultural em Psicologia Cognitiva da Universidade Federal de Pernambuco. Analista Judiciário; Psicólogo do Tribunal de Justiça de Pernambuco. Recife/PE, Brasil. E-mail: nemesiodario@hotmail.com. 